[Technical Paper]

\title{
Bondability Investigations of Thermosonic Flip Chip Bonding Using Ultrasonic Vibration Perpendicular to the Interface
}

\author{
Taizo Tomioka* and Ikuo Shohji** \\ *Toshiba Corporation, Shinisogo-cho 33, Isogo-ku, Yokohama-shi, Kanagawa 235-0017, Japan \\ **Gunma University, Tenjin-cho 1-5-1, Kiryu-shi, Gunma 376-8515, Japan
}

(Received November 9, 2018; accepted March 4, 2019, published April 2, 2019)

\begin{abstract}
This paper describes the bondability of thermosonic flip chip bonding, in which ultrasonic (US) vibration perpendicular to the interface was applied. Experiments were carried out with a device chip having 11 Au stud bumps and a ceramic substrate having Au-plated bonding pads. The stud bump was used to investigate bondability when the bump was largely deformed. The height reduction ratio of the bump was changed from $38 \%$ to $64 \%$ by changing bonding load and US amplitude. The relationship between the height reduction ratio of bump and shear strength of the bond was compared with that using US parallel to the interface. It was found that the bonding using US vibration perpendicular to the interface requires bonding load and US amplitude above a certain level to obtain high bond strength. When the height reduction ratio of the bump became bigger than $60 \%$, bond strength of approximately $100 \mathrm{MPa}$ was obtained. This strength was higher than bond strength of the bonding using US vibration parallel to the interface.
\end{abstract}

Keywords: Flip Chip Bonding, Thermosonic Bonding, Au Stud Bump, Direction Of Ultrasonic Vibration, Perpendicular, Parallel, Ceramic Substrate

\section{Introduction}

Thermosonic flip chip bonding is one of the common processes to connect the device chip and the substrate. Comparing with other processes such as soldering and conductive adhesive, thermosonic bonding could provide a shorter process time with less contamination of the device chip.[1] Therefore, it has been used in VCSELs, [2] SAW filters [3, 4] and MEMS chips[5] which are relatively inexpensive and sensitive to contamination.

In usual thermosonic flip chip bonding, the device chip is pressed by the bonding tool, then US vibration in the direction parallel to the interface as shown in Fig. 1 (the parallel US bonding) is applied to the device chip. The US vibration is transferred from the bonding tool to the device

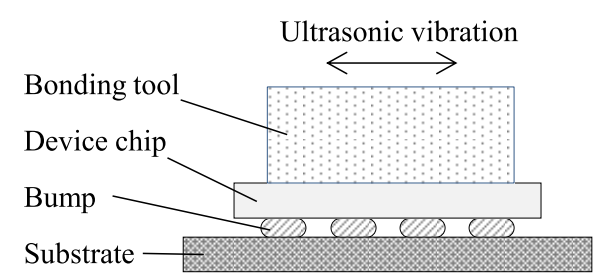

Fig. 1 Bonding using US vibration parallel to the bonding interface. chip. The transmission efficiency of the US vibration depends on the friction between the bonding tool and the device chip. Accordingly, the amplitude of the device chip could be varied because of the changing of the surface properties of the bonding tool and the device chip. In addition, Maeda et al. reported that the bond strength of the bump and the bonding pad depends on the longitudinal direction of the substrate pad.[6] The bond strength with the bonding pad which is longitudinal in the direction perpendicular to the US vibration became lower than that with the bonding pad which is longitudinal in the direction parallel to the US vibration. These problems can be solved by the application of the US vibration which is perpendicular to the interface (the perpendicular US bonding).

Bonding of the bump and the bonding pad are formed by destroying inhibitors such as the oxidation layer by plastic deformation at the interface.[7] In the bonding process, the US vibration facilitates the plastic deformation of the interface. The US vibration decreases the deformation resistance of the bump,[8] therefore the contact area expands larger than that when only the bonding load is applied. Takahashi et al. clarified by the numerical analysis 
that the bump surface of the contact edge expands and the bonding pad surface shrinks in the expanding process of the parallel US bonding.[9] Moreover, the parallel US bonding can cause the gross sliding at the interface with some bonding conditions. $[10,11]$ The gross sliding possibly obtains high bond strength due to plastic deformation on the nearly entire interface. Although the perpendicular US bonding can not cause the gross sliding, it can cause the plastic deformation by increasing of the contact area between the bump and the bonding pad. In addition, the plastic deformation at the center of the contact area is expected to progress due to the application of the vibration even if the bump is largely deformed. Therefore, sufficient bonding strength could be able to obtain, even by the perpendicular US bonding.

Flip chip bonding by the perpendicular US bonding was shown by Tan et al.[12] The SRAM chip with Au-plated bump was used in the bonding experiment and shear force of approximately $0.1 \mathrm{~N}$ was obtained. However, electronic device chips with a small number of bumps require higher bond strength. In the case of SAW filters, it was reported that the shear force of $0.4 \mathrm{~N}$ per bump was obtained to ensure the reliability.[3] When the contact diameter between the bump and the substrate pad is $100 \mu \mathrm{m}$, the shear force of $0.4 \mathrm{~N}$ corresponds to the bond strength of $51 \mathrm{MPa}$. To obtain higher bond strength, enlarging bump deformation is effective. When a bump deformed largely by the parallel US bonding, deformation in the center portion of the interface between a bump and a bonding pad becomes difficult to advance.[9] In contrast to that, the perpendicular US bonding is expected to progress plastic deformation in the center of the interface even if the bump is largely deformed. However, there has been no study focused on obtaining high bond strength of the perpendicular US bonding.

In this study, bonding with large bump deformation was performed to confirm that the perpendicular US bonding can obtain high bond strength. An Au stud bump which has high deformability than an Au plated bump was used in the experiment. Bump deformation value was varied by changing the bonding load and US amplitude. Bond strength was measured by the shear test. The relationship between bump deformation value and bond strength was compared with that of the parallel US bonding.

\section{Experiments}

\subsection{Specimens}

The specifications of the test chip used in bonding
Table 1 Specifications of the test chip and the test substrate.

\begin{tabular}{ll}
\hline \multicolumn{1}{c}{ Items } & \multicolumn{1}{c}{ Specifications } \\
\hline [Chip] & $1.9 \times 1.4 \times 0.4\left[\mathrm{~mm}^{3}\right]$ \\
Chip size & $\mathrm{Al}-0.5 \mathrm{Si}-0.5 \mathrm{Cu}\left[\mathrm{mass}^{2}\right]$ \\
Pad material & $0.7[\mu \mathrm{m}]$ \\
Pad thickness & 11 \\
Pin count & \\
[Substrate] & $\mathrm{W} / \mathrm{Ni} / \mathrm{Au}$ \\
Pad layer composition & $1.5 / 2.0 / 2.5[\mu \mathrm{m}]$ \\
Thickness of each layer & \\
\hline
\end{tabular}

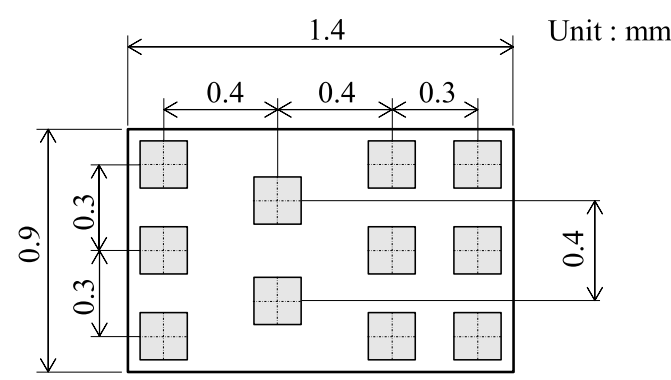

Fig. 2 Layout of the bonding pad.

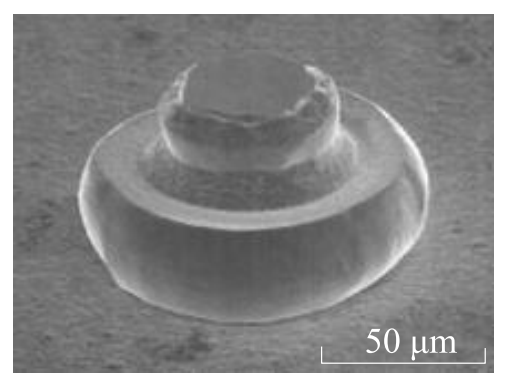

Fig. 3 Au stud bump.

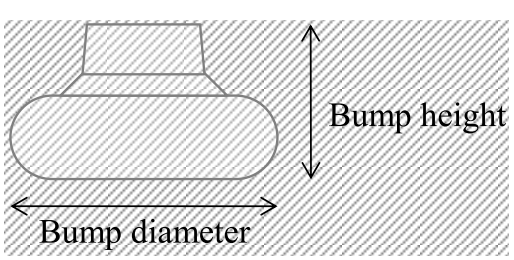

Fig. 4 Shape of the Au stud bump.

experiments are shown in Table 1 . The surface roughness, Ra of the chip back was $0.6 \mu \mathrm{m}$. Figure 2 shows the bonding pad layout of the test chip. The size of the bonding pad is $175 \mu \mathrm{m}$ squares. The bonding pad was $\mathrm{Al}-0.5 \mathrm{Si}-0.5 \mathrm{Cu}$ (mass\%) film formed by sputtering. The stud bump shown in Fig. 3 was formed on each bonding pad using a wirebonder. 99.99 mass\% purity Au wire of $\phi 25 \mu \mathrm{m}$ was used for stud bump formation. The upper part of the stud bump was flattened and the height of the bump was uniformed using the flip chip bonder before bonding. The bump's average diameter shown in Fig. 4 was $108 \mu \mathrm{m}(\sigma=1.4)$, the bump's average height was $51 \mu \mathrm{m}(\sigma=0.8)$. The bump 


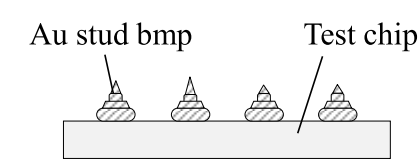

Bumping
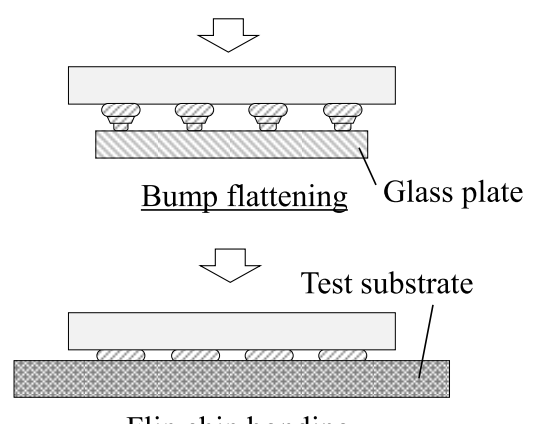

Flip chip bonding

Fig. 5 Bonding procedure.

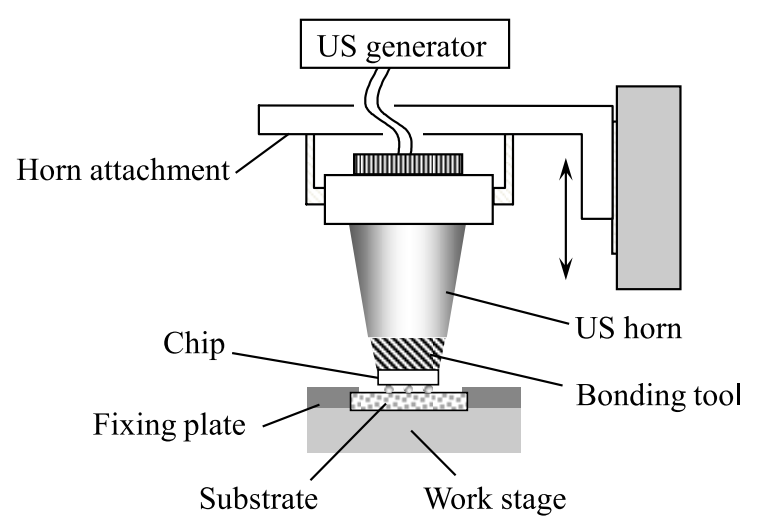

Fig. 6 Schematic of the thermosonic flip chip bonder. (version of perpendicular US bonding)

diameter and the bump height were measured using the measuring microscope. The test substrate was made of ceramics. The bonding pad on the substrate was formed on the entire surface of the substrate (not patterned) to avoid unevenness. The bonding pad composition was $\mathrm{W} /$ $\mathrm{Ni} / \mathrm{Au}$ from the ceramic side. Thickness of each layer was 15, 2.0, $2.5 \mu \mathrm{m}$ respectively. The Au and the Ni layer were formed by electroplating. The $\mathrm{W}$ layer was formed by sintering as the same time as ceramics.

\subsection{Bonding procedure}

Bonding procedure is shown in Fig. 5. After bumping, the test chip was flipped upside down and was pressurized at load of a $1.0 \mathrm{~N} /$ bump to the flat glass plate. Then, the test chip was bonded to the heated ceramic test substrate using US vibration. Figure 6 shows the schematic of the thermosonic flip chip bonder. This bonder consisted of the pressurization mechanism, the US generator, the US horn, the work stage and the alignment camera. US frequency was approximately $61 \mathrm{kHz}$. Attaching direction of the ultrasonic horn to the pressurization mechanism was changed

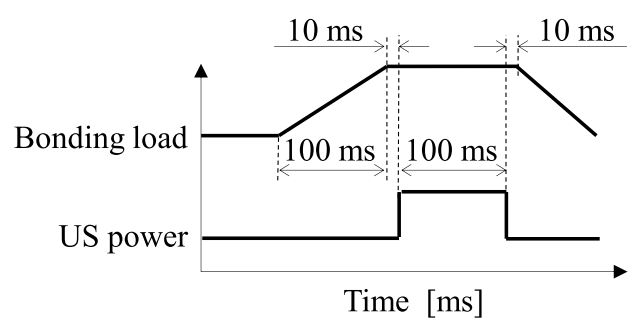

Fig. 7 Profiles of bonding load and US power.

by using two kinds of attachment. The surface roughness, Ra of the bonding tool was $0.9 \mu \mathrm{m}$. The test chip was vacuum-chucked to the bonding tool and the substrate was fixed on the work stage by the mechanical chuck and the vacuum chuck. The profile of the bonding load and the ultrasonic power is shown in Fig. 7. The time from the bump contacting to the reaching of the set bonding load was $100 \mathrm{~ms}$, and applying time of US vibration (bonding time) was $100 \mathrm{~ms}$. A dwell time of $10 \mathrm{~ms}$ was set before and after the bonding time. Bonding load per a bump was changed from $0.5 \mathrm{~N}$ to $2.5 \mathrm{~N}$. US amplitudes of $1.4 \mu \mathrm{m}, 1.9$ $\mu \mathrm{m}, 2.4 \mu \mathrm{m}, 2.8 \mu \mathrm{m}$, and $3.1 \mu \mathrm{m}$ were used. These US amplitudes are the values of peak to peak with no load condition. US amplitudes were measured at the end face of the bonding tool in the case of perpendicular horn setting, and measured at the lateral face of the bonding tool tip in the case of parallel horn setting.

\subsection{Evaluation method}

The shear force of the bond and the bump height were measured. The shear force was measured by the die-shear test. In this paper, we defined breaking force divided by the number of the bump as a shear force of the bond. The bond strength was calculated by dividing the shear force by the contact area between each bump and bonding pad. The die-shear test was carried out by moving horizontally the shear tool at $500 \mu \mathrm{m} / \mathrm{s}$ in speed. The shear tool tip was set to the $50 \mu \mathrm{m}$ upper from the bonding pad of the test chip. Bonding samples were separated by removing aluminum bonding pad of the test chip by etching. Then, heights of bumps remaining on the test substrate were measured using the measuring microscope. The height reduction ratio of bump, $\mathrm{Hr}$ calculated by the formula shown in the (1) equation was used to evaluate the bump deformation value. Four bumps of each corner were measured and the average was calculated.

$$
\begin{aligned}
& H \mathrm{r}=\left(H_{0}-H_{\mathrm{b}}\right) / H_{0} \times 100 \\
& H_{0}: \text { Initial height of bump }(\mu \mathrm{m}) \\
& H_{\mathrm{b}} \text { : Bump height after bonding }(\mu \mathrm{m})
\end{aligned}
$$

In order to determine the contact area of the bump and 


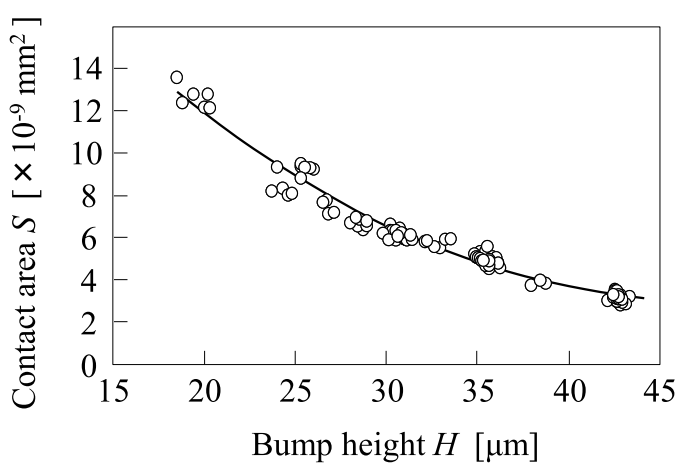

Fig. 8 Relationship between bump height $H$ and contact area $S$ per bump.

the bonding pad from bump height, the relational expression of these was investigated beforehand. The contact area $(S)$ and bump height $(H)$ were measured by pressing the bump to the flat glass plate by various loads. The contact area $(S)$ was calculated by image processing with the captured image of the bump planarized by pressing. The relationship between the bump height $(H)$ and the contact area $(S)$ is shown in Fig. 8. The approximate equation (2) was obtained from the graph. Then, the contact area $(S)$ was calculated from the bump height after bonding using this equation.

$$
\begin{aligned}
& S=\left(0.012 \times H^{2}-1.129 \times H+29.59\right) \times 10^{-9} \\
& S: \text { Contact area }\left(\mathrm{m}^{2}\right) H: \text { Bump height }(\mu \mathrm{m})
\end{aligned}
$$

\section{Results and Discussion}

Figure 9 shows the effect of the bonding load on the shear force by the perpendicular US bonding and the parallel US bonding with US amplitude of $2.4 \mu \mathrm{m}$. The shear force increased as the bonding load became larger in both US vibration directions. The bond between the bump and the substrate bonding pad fractured when the bonding load was in the range of $0.5 \mathrm{~N}$ to $1.5 \mathrm{~N}$. When the bonding load was $2.0 \mathrm{~N}$ and $2.5 \mathrm{~N}$, fractures between the bump and the substrate pad and fractures between the bump and the chip pad coexisted. Figure 10 shows the height reduction ratio of bumps. The height reduction ratio of the parallel US bonding increased, as the bonding load became larger. On the other hand, that of the perpendicular US bonding showed low dependence on the bonding load. This is considered that bumps deform even by low bonding load due to hammering effect in the perpendicular US bonding.[13] Figure 11 shows the relationship between bond strength and bonding load. The bond strength is calculated by dividing the average shear force by the contact area calculated from the average bump height. The bond strength of

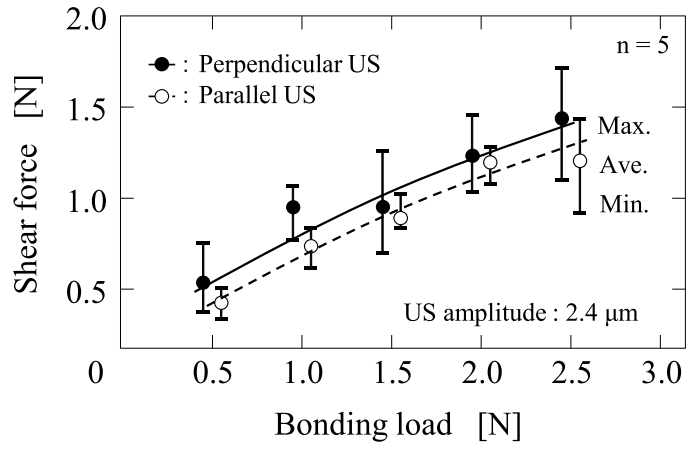

Fig. 9 Effect of bonding load on shear force.

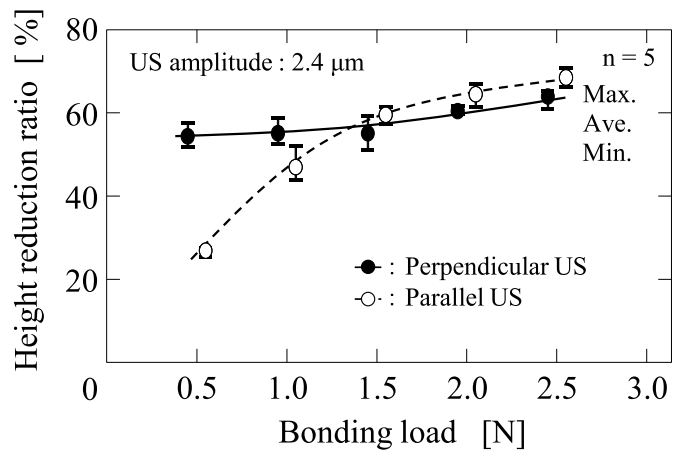

Fig. 10 Effect of bonding load on height reduction ratio of bump.

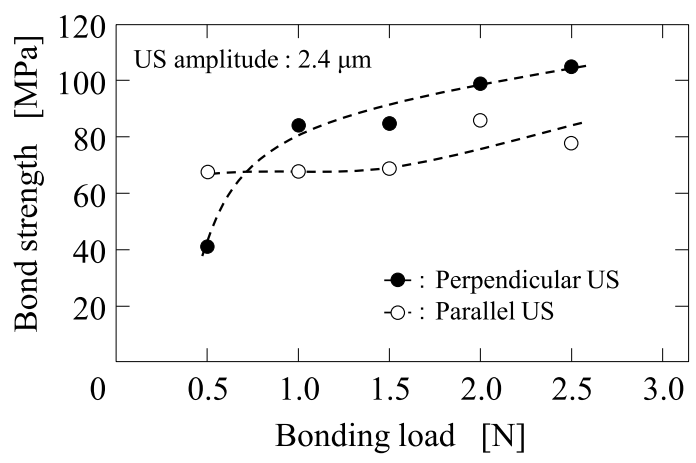

Fig. 11 Relationship between bonding load and bond strength.

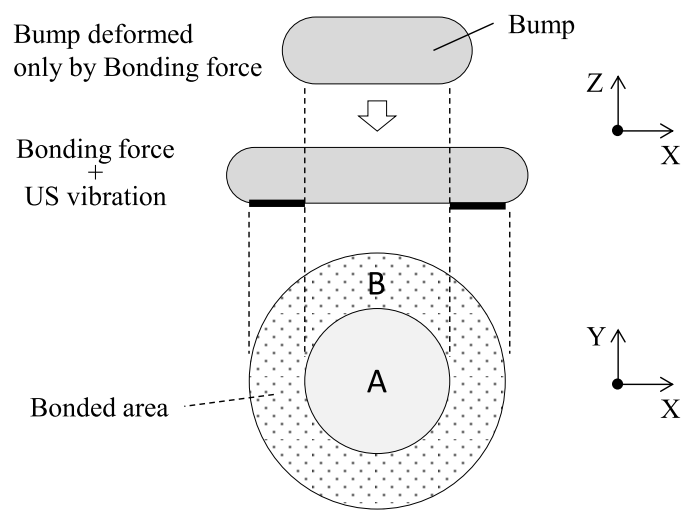

Fig. 12 Schematic of bonded area by the parallel US bonding. $\mathrm{A}+\mathrm{B}=$ Contact area

$\mathrm{B}=$ Bonded area 
the parallel US bonding did not increase largely with increasing the bonding load.

Figure 12 shows the schematic of the bonded area by the parallel US bonding. The area A is the contact area generated by only the bonding load. The area B is the increased contact area by application of US vibration. In the case of large bump deformation, the area A is hardly bonded,[14] bonding mainly proceeds in the area B. Here, the area $\mathrm{A}$ and the bonding load have an almost proportional relationship.[15] In addition, the area B is almost proportional to the bonding load, too.[16] Thus, the ratio of the area $\mathrm{B}$ to the contact area $(\mathrm{A}+\mathrm{B})$ becomes nearly constant even if the bonding load is changed. For this reason, the bond strength of the parallel US bonding is considered to become small change. On the contrary, the bond strength of the perpendicular US bonding, increased with increasing the bonding load. In the bonding load range more than $1.0 \mathrm{~N}$, the bond strength of the perpendicular US bonding became more than $80 \mathrm{MPa}$, and it was higher than that of the parallel US bonding. Furthermore, when the bonding load was $2.0 \mathrm{~N}$ or more, the bond strength reached $100 \mathrm{MPa}$. This seems to indicate that the plastic deformation proceeds at both center and perimeter regions of the contact area by the perpendicular US bonding.

Figure 13 shows the effect of the US amplitude on the shear force. The bonding load was $1.5 \mathrm{~N}$. The shear force increased up to the US amplitude of $2.8 \mu \mathrm{m}$ and then saturated. Figure 14 shows the effect of the US amplitude on the height reduction ratio of the bump. In both the perpendicular US bonding and the parallel US bonding, fracture of the bond occurred between the bump and the substrate pad in the range of US amplitude $1.4 \mu \mathrm{m}$ to $2.4 \mu \mathrm{m}$. When the US amplitude was $2.8 \mu \mathrm{m}$ and $3.1 \mu \mathrm{m}$, the number of fractures between the bump and the chip pad exceeded that between the bump and the substrate pad. This means that the shear strength at US amplitude above $2.8 \mu \mathrm{m}$

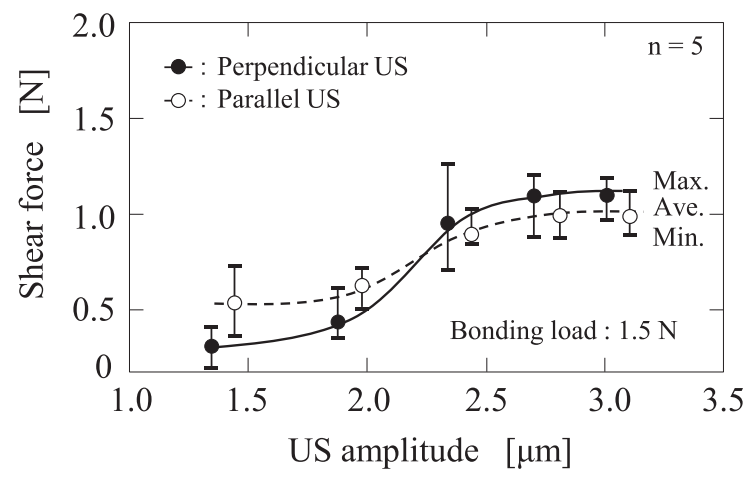

Fig. 13 Effect of US amplitude on shear force. mainly shows the shear strength between the bump and the chip pad. This is the reason why the shear strength becomes saturated. With increasing the US amplitude, the height reduction ratio of the bump increased. Unlike shear force, the height reduction ratio did not saturate. Figure 15 shows the relationship between the US amplitude and the bond strength. The bond strength is calculated by dividing the average shear force by the contact area calculated from the average bump height. In the perpendicular US bonding, when the US amplitude is smaller than $1.9 \mu \mathrm{m}$, the bonding strength was lower than that of the parallel US bonding and did not increase much with increasing the US amplitude. In the US amplitude range of $1.9 \mu \mathrm{m}$ to $2.4 \mu \mathrm{m}$, the bond strength increased significantly and became higher than that of the parallel US bonding. From this result, the following bonding behavior could be considered. When the US amplitude is less than $2.4 \mu \mathrm{m}$, bonding of the perpendicular US bonding, mainly proceeds at the perimeter contact area as same as the parallel US bonding. The bonding efficiency of the perpendicular US bonding is lower than that of the parallel US bonding in this phase. When the US amplitude becomes higher than $2.4 \mu \mathrm{m}$, the center contact area begun to be bonded and then the bond

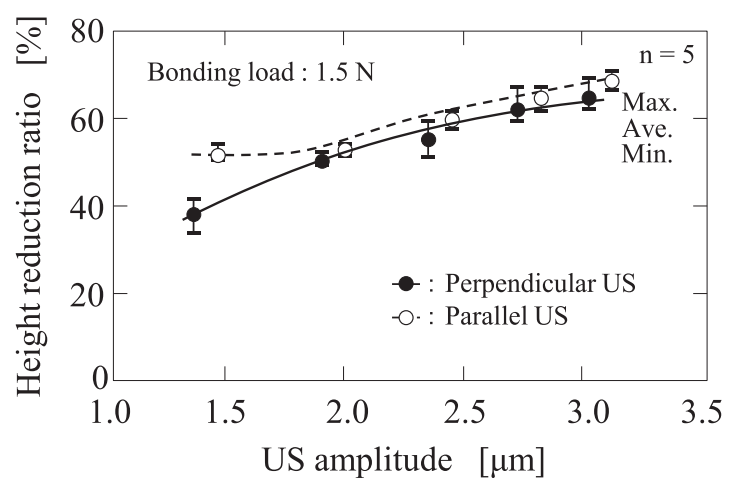

Fig. 14 Effect of US amplitude on height reduction ratio of bump.

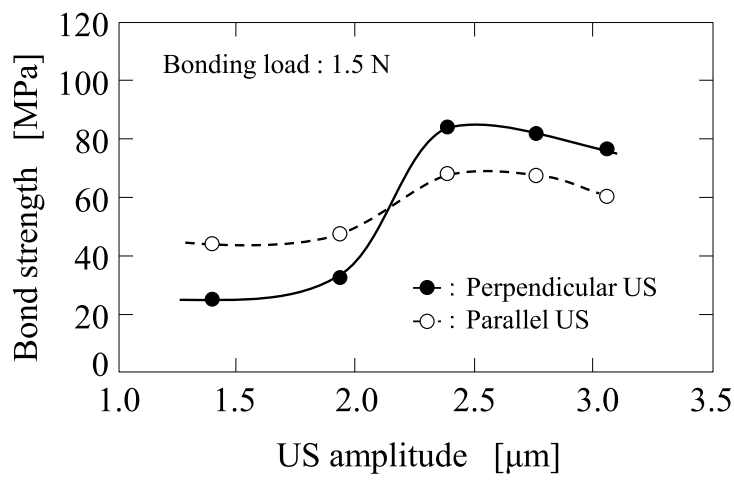

Fig. 15 Relationship between US amplitude on bond strength. 


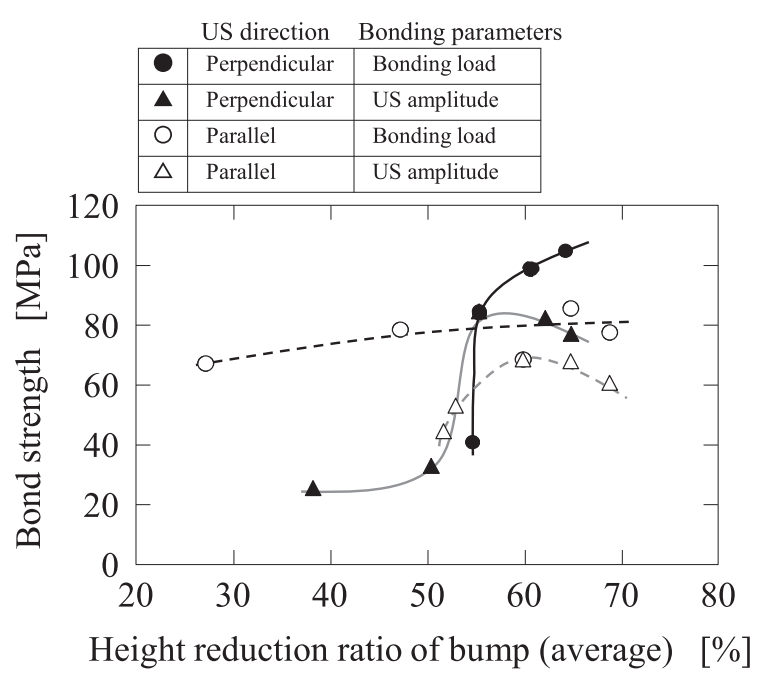

Fig. 16 Relationship between height reduction ratio and bond strength.

strength increased. In other words, progress of adhesion at the interface could be considered to require impact above a certain level. In addition, The reason why the bonding strength decreases at $2.8 \mu \mathrm{m}$ or more is that the contact area increases as US amplitude increases, but the shear force saturates. The saturation of the shear force is considered to be due to the occurring of fracture of the bond between the bump and the chip's bonding pad by the die shear test.

Figure 16 shows the relationship between the bond strength and the height reduction ratio of bumps. The bond strength is calculated by dividing the average shear force by the contact area calculated from the average bump height. The average bump height reduction rate varied from $38 \%$ to $64 \%$ for the perpendicular US bonding and from $27 \%$ to $69 \%$ for the parallel US bonding. The parallel US bonding obtained bond strength of more than $60 \mathrm{MPa}$ at the height reduction ratio less than $30 \%$. Even if the height reduction ratio increases, the bond strength of the parallel US bonding does not largely increase. The bond strength became approximately $80 \mathrm{MPa}$ at the height reduction ratio of $60 \%$. The saturation bond strength of bonding a chip having 6 bumps to a ceramic substrate having Au-plated pads heated to $200^{\circ} \mathrm{C}$ by bonding time of 500 ms was $1.9 \mathrm{~N}$ with a bump diameter of $165 \mu \mathrm{m}$.[17] The bonding strength is roughly calculated to be $84 \mathrm{MPa}$. Thus, the bonding strength obtained even by the short bonding time of $100 \mathrm{~ms}$ in this study is considered to be a reasonable value. In contrast, the bond strength of the perpendicular US bonding is low when the height reduction ratio of the bump is low. However, in the range of more than $60 \%$ of the height reduction ratio of the bump, the bond strength of the perpendicular US bonding becomes higher than that of the parallel US bonding, and reaches to $100 \mathrm{MPa}$.

From these results, it was confirmed that flip chip bonding of the perpendicular US vibration can obtain higher bond strength than the parallel US bonding in the large bump deformation range. In addition, the effect of the bonding load and the US amplitude on the bump deformation and the bond strength were clarified. The bonding load of more than $2.0 \mathrm{~N}$ and the US amplitude of more than $2.4 \mu \mathrm{m}$ is required in order to obtain the bond strength of $100 \mathrm{MPa}$.

Further research should be conducted on the distribution of plastic deformation at the bonding interface. Fujii $e t$ $a l$. reported that crystal grains in the vicinity of the bonding interface were refined in ultrasonic bonding.[18] Because recrystallization occurs as a result of plastic deformation, it could be considered to be possible to estimate the distribution of the plastic deformation at the bonding interface by examining the grain size. To investigate the distribution of the size of crystal grains near the bonding interface, and verify the plastic deformation behavior of the interface in perpendicular US bonding inferred in this study, further study would be required.

\section{Conclusion}

This study shows the potential of the thermosonic flip chip bonding by using the ultrasonic vibration perpendicular to the bonding interface which could achieve higher bond strength than that of by using the ultrasonic vibration parallel to the interface. The relationship between the bond strength and the height reduction ratio of the $\mathrm{Au}$ stud bump was investigated and compared with that by using ultrasonic vibration parallel to the interface. The following results were obtained.

(1) The bonding using ultrasonic vibration perpendicular to the interface requires bonding loads of more than $2.0 \mathrm{~N}$ per bump and ultrasonic amplitude of more than $2.4 \mu \mathrm{m}$ to obtain high bond strength.

(2) Bond strength of $100 \mathrm{MPa}$ was obtained when the height reduction ratio of the bump was over $60 \%$. This strength was higher than that of the bonding using the ultrasonic vibration parallel to the interface.

\section{References}

[1] S. Y. Kang, W. Zhang, and Y. C. Lee, "Thermosonic Bonding for Flip-chip Assembly,” Proc. IEEE 
MCMC-95, pp. 75-80, 1995.

[2] T. S. McLaren, S. Y. Kang, W. Zhang, T. H. Ju, and Y. C. Lee, "Thermosonic Flip-chip Bonding of an Optical Transceiver Based on an $8 \times 8$ Vertical Cavity Surface Emitting Laser Array,” IEEE Trans. Comp. Pack. Manuf. Tech., Vol. 20-2, pp. 152-159, 1997.

[3] H. Yatsuda and T. Eimura, "Flip-Chip Assembly Technique for SAW Devices,” Proc. ISHM'95, pp. 365-370, 2003.

[4] T. Tomioka, T. Iguchi, and I. Mori, "Thermosonic Flip-chip Bonding for SAW Filter,” Microelectronics Reliability, Vol. 44, pp. 149-154, 2004.

[5] K. Nakano, N. Fujimoto, M. Tanaka, and A. Asai, "Development of The Ultrasonic Flip Chip Bonding Technology for Yaw Rate Sensors,” DENSO TECHNICAL REVIEW, Vol. 21, pp. 150-155, 2016.

[6] T. Maeda, K. Yano, R. Morimoto, and J. Hirota, "Development of Ultrasonic Flip Chip Bonding Technology for Plastic Circuit Board," Proc. 10th Microjoining and Assembly Technology in Electronics Symp., pp. 265-270, 2004.

[7] A. Ishizaka, S. Iwata, and H. Yamamoto, "Formation of Clean Al Surface by Interface Deformation in Au-Al Thermo-Compression Bonding,” J. Jpn. Inst. Met., Vol. 41, pp. 1154-1160, 1977.

[8] F. Blaha and B. Langenecker, "Ultrasonic Investigation of The Plasticity of Metal Crystals,” Acta Mater., Vol. 7-2, pp. 93-100, 1959.

[9] Y. Takahashi, T. Kameda, and S. Aratani, "Numerical Study of Interfacial Deformation during Thermosonic Micro-bonding," Proc. 9th Microjoining and Assembly Technology in Electronics Symp., pp. 67-72, 2003.

[10] I. Lum, J. P. Jung, and Y. Zhou, "Bonding Mechanism in Ultrasonic Gold Ball Bonds on Copper Substrate," Metall. Mater. Trans., Vol. 36, pp. 1279-1286, 2005.

[11] H. Horibe, K. Nakamura, and T. Akiyama, "New Wire Technology for Fine Pad Pitch,” Proc. The 3rd VLSI Packaging Workshop of Japan, pp. 15-17, 1996.

[12] Q. Tan, W. Zhang, B. Schaible, and L. J. Bond, "Thermosonic Flip-Chip Bonding using Longitudinal Ultrasonic Vibration,” IEEE Trans. Comp. Pack. Manuf. Tech., Vol. 21-1, pp. 53-58, 1998.

[13] Y. Tanaka and M. Ido, "Plastic Deformation of Metal Surface Induced by Ultrasonic Hammering,” J. Jpn. Soc. of Prec. Eng., Vol. 38-8, pp. 631-637, 1972.

[14] T. Tomioka, T. Iguchi, and I. Shohji, "Effect of Bond Force Profile on Bondability of Thermosonic Flip Chip Bonding,” Q. J. Jpn. Weld. Soc., Vol. 36-1, pp. 16-20, 2018.

[15] J. Greer, W. Oliver, and W. Nix, "Size Dependence of Mechanical Properties of Gold at the Micron Scale in the Absence of Strain Gradients,” Acta Mater., Vol. 53-6, pp. 1821-1830, 2005.

[16] T. Tomioka, T. Iguchi, and I. Shohji, "Robustness Improvement of Thermosonic Flip Chip Bonding to Device Chip Tilt (in press),” J. Jpn. Soc. Technol. Plast.

[17] T. Tomioka, T. Iguchi, and K. Atsumi, "Effect of Bump Condition on Flip-Chip Bondability,” J. High Temp. Soc., Vol. 30-1, pp. 41-46, 2004.

[18] H. Fujii, S. Shimizu, Y. Sato, and H. Kokawa, "HighStrain-Rate Deformation in Ultrasonic Additive Manufacturing,” Scr. Mater., Vol. 135, pp. 125-129, 2017.

\section{Taizo Tomioka}

Ikuo Shohji 